\title{
Turbidity removal by rapid sand filter using anthracite coal as capping media
}

\author{
Gopal Tamakhu ${ }^{a, *}$, Iswar Man Amatya ${ }^{b}$ \\ ${ }^{a}$ Department of Environmental Engineering, Pulchowk Campus, Institute of Engineering, Tribhuvan University, Lalitpur, Nepal \\ ${ }^{b}$ Department of Civil Engineering, Pulchowk Campus, Institute of Engineering, Tribhuvan University, Lalitpur, Nepal
}

\section{ARTICLE INFO}

\section{Article history:}

Received 08 Dec 2020

Received in revised form

$04 \mathrm{Feb} 2021$

Accepted $14 \mathrm{Feb} 2021$

Keywords:

Capping

Filter run time

Anthracite coal

Rapid sand filters

Turbidity removal

\begin{abstract}
Rapid sand filters are very common in all conventional water treatment plants. Capping of existing rapid sand filters can be the promising method of improving the performance of rapid sand filters. Capping is process in which upper sand bed layer of few $\mathrm{cm}$ is replaced with capping material. However, this technique is limited in Nepal due to unavailability of filter materials apart from sand. Some materials suitable for capping are anthracite coal, PVC granules, bituminous coal, broken bricks, etc. The attempt is made to study the effect of capping of Rapid sand filters by the use of anthracite coal as a capping media by pilot scale study. A series of test runs and experiments using different influent turbidity were tried. The pilot scale study has shown very encouraging results. Comparative analysis shows that higher rate of filtration is possible along with higher filter run and less backwash requirement. In the present work, conventional rapid sand filter and capped rapid sand filter are compared.
\end{abstract}

\section{Introduction and Literature Review}

High turbidity is one of the main characteristics of the surface water sources. Material that causes water to be turbid includes clay, silt, finely divided inorganic and organic matter, algae, soluble colored organic compounds, and plankton and other microscopic organisms. Granular filtration is the process whereby water is purified by passing it through a porous material [1]. S.M. Al-Rawi [2] performed an experiments on sand filter capping on the pilot plant constructed similar to the existing water treatment plants of Mosul/Iraq. The literature showed the anthracite capping filters were proven to suitably operate under varying conditions of influent turbidity and filtration rates. Economic revenue was gained through reduction of disinfection doses as well as reduction in filter sand material [2].

Capping of existing rapid sand filters can be the promis-

\footnotetext{
*Corresponding author:

@maunatagotam4uegmail.com (G. Tamakhu)
}

CJIEE Thapathali Campus, IOE, TU. All rights reserved

ing method of improving the performance of rapid sand filters [3]. The idea behind these filters is that the lighter media of larger size occupy the upper layers of the filter, allowing greater penetration of the floc. Capping is a process of covering the filtration media by appropriates caps such as Anthracite coal, Bituminous coal, Crushed coconut shells, etc. [3]. Anthracite typically functions as top coarse layer in dual or multimedia beds to provide storage volume for large amount of solids (thus providing long filter runs) while the under laying sand media provides a finer filter media to stop solids passing all the way through the anthracite [4]. The anthracite having lower specific gravity will float on top of the higher specific gravity sand. If an increase in capacity is desired in such technology, a larger amount of sand is replaced as such practice will increase filter run as well as it will increase the amount of fines [2].

\section{Rationale of the Study}

Turbidity is the principle parameter, which refers to water containing suspended matters or impurities that interferes with the light transmission through water. It 
reduces aesthetic acceptability, filterability and disinfection potential of drinking water. Turbidity removal is a major challenge in water supply schemes in Nepal where streams or river are the sources of supply. Most current existing plants turned incapable of tackling problems related to proper water treatment like, mud ball formation, unsatisfactory effluent, higher backwash water requirement, insufficient for increased demands and bad overall performance. Use of capping media in conventional Rapid Sand Filter is better from the point of view of the rate of filtration as well as total filter run. The use of such techniques is limited in Nepal due to unavailability of filter materials apart from sand.

This paper aims to use anthracite coal as capping media to investigate its performance against conventional rapid sand filter. This paper focuses on effectiveness of this technology in turbidity removal at varying inflow turbidity.

\subsection{Methodology}

\subsubsection{Experimental Set-Up}

The schematic diagram of a pilot scale set up of two rapid sand filters having internal dimensions $(11 \times 11$ $\times 290) \mathrm{cm}^{3}$ is shown in Figure 1 .

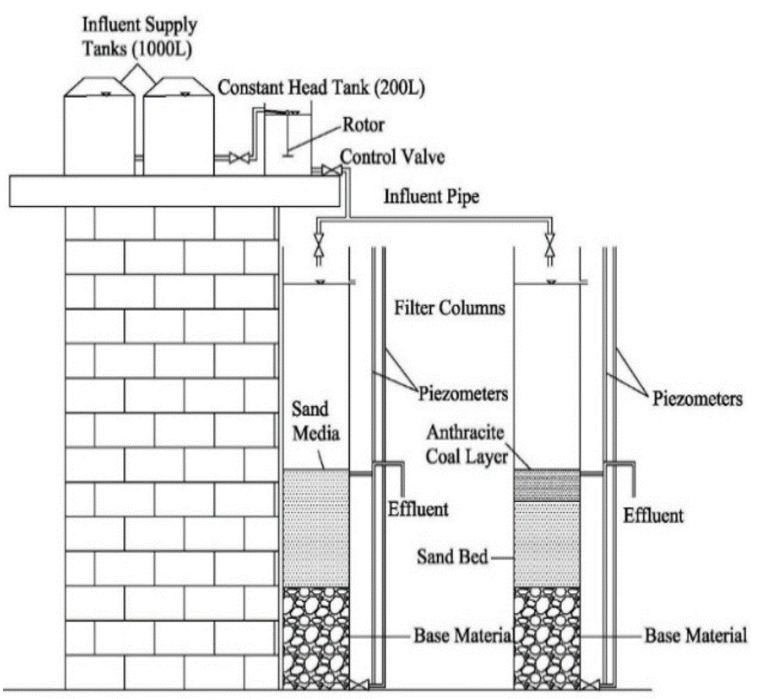

Figure 1: Experimental setup

The Rapid Sand Filter has been designed for the filtration rate of $3000 \mathrm{lit} / \mathrm{m}^{2} / \mathrm{hr}$. The filter models were setup in Water Treatment plant, Institute of Engineering premise. Sand and anthracite coal were sieved through series of sieves of sizes $2 \mathrm{~mm}, 1 \mathrm{~mm}, 0.6 \mathrm{~mm}, 0.425$ $\mathrm{mm}$ and $0.3 \mathrm{~mm}$. After drying, they were mixed in fixed proportion by weight to create $1 \mathrm{~kg}$ batch Sand of Uniform Coefficient (Uc) of 1.54 and effective size (E.S) of $0.5 \mathrm{~mm}$. For anthracite coal, effective size of 0.91 $\mathrm{mm}$ and Uniform Coefficient (Uc) of 1.33 was prepared with same procedure

Each model consists of altogether six ports, three at 5 $\mathrm{cm}$ above the base of filter on three different faces for outlet, piezometer and backwashing purposes, fourth at height of $115 \mathrm{~cm}$ from base for piezometer, fifth at height of $135 \mathrm{~cm}$ from base for backwash effluent and sixth at height of $285 \mathrm{~cm}$ from base for influent overflow. The effluent level was kept $10 \mathrm{~cm}$ above the filter media to keep minimum of $10 \mathrm{~cm}$ water level above the filter media in order to keep media wet and to avoid development of negative head loss in the filter media.

\subsection{Experimental Procedure}

Synthetic water was prepared by adding sludge in natural water, extracted from ground water storage tank. Hit and trial method was used to calculate amount of mud slurry required to prepare the artificial suspension. The mixing tank was stirred continuously using rotor. The resistance developed during filtration will be compensated by increase in water level above the filter media keeping constant filtration rate of $3 \mathrm{~m} / \mathrm{hr}$. Head loss development during filter run was measured using piezometer and turbidity was measured by Turbidity meter Model 2100A.

\subsection{Experimental Conditions}

The filters were operated intermittently and filter runs were terminated when the terminal head of $165.4 \mathrm{~cm}$ was exhausted, irrespective of filter effluent turbidity value. Filters were backwashed after exhaustion in order to remove the trapped solids in filter media with backwashing velocity of $24 \mathrm{~m} / \mathrm{hr}$. The end of backwashing operation was judged by viewing the clarity of backwash effluent. Table 1 presents the set conditions of filter media and base materials for both filters.

\section{Result and Discussion}

Seven filter runs were performed with influent turbidity of 0-25, 25-50, 50-100, 100-150, 150-200, 200-250 and 250-300 Nephelometric Turbidity Units (NTU). Comparative study of both filters is done for different parameters like turbidity removal, head loss development and filter run length. The results of the experiments for both filters are discussed and presented graphically.

\subsection{Effluent Turbidity during Filter Run time}

In first filter run, the average influent turbidity for Sand and capped filter was 10.9 NTU. The average effluent turbidity for Sand was 1.21 NTU and for Capped filter was 0.88 NTU as shown in Figure 2.

In seventh filter run, average influent turbidity for Sand 
Turbidity removal by rapid sand filter using anthracite coal as capping media

Table 1: Filter media and base materials used in filter models

\begin{tabular}{llll}
\hline Filter Material & $\begin{array}{l}\text { Size } \\
(\mathrm{mm})\end{array}$ & $\begin{array}{l}\text { Sand Filter, } \\
\text { Depth }(\mathrm{cm})\end{array}$ & $\begin{array}{l}\text { Anthracite Capped } \\
\text { Filter Depth }(\mathrm{cm})\end{array}$ \\
\hline Anthracite Coal $(\mathrm{Uc}=1.33)$ & $0.91($ E.S.) & - & 20 (capping layer) \\
Sand (Uc=1.54) & $0.5($ E.S.) & 60 & 40 \\
Gravel, Base Material Layer 1 & $2-4.75$ & 10 & 10 \\
Gravel, Base Material Layer 2 & $4.75-10$ & 10 & 10 \\
Gravel, Base Material Layer 3 & $10-20$ & 10 & 10 \\
Gravel, Base Material Layer 4 & $20-28$ & 10 & 10 \\
Gravel, Base Material Layer 5 & $28-40$ & 10 & 10 \\
\hline
\end{tabular}

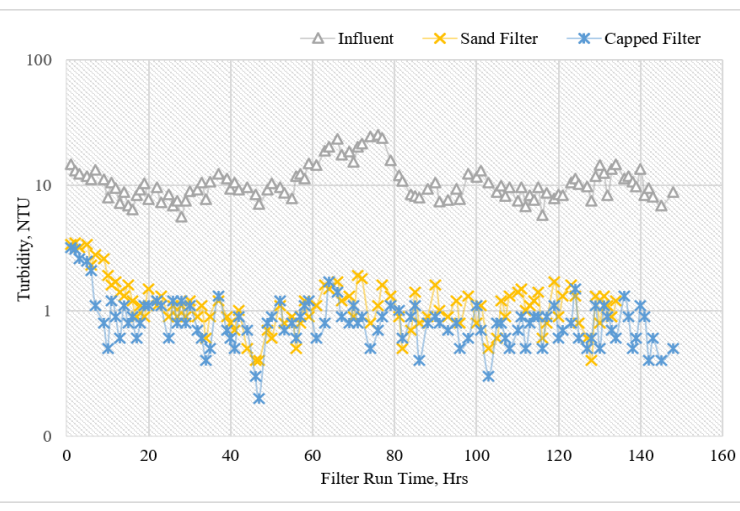

Figure 2: Effluent turbidity during first filter run

and Capped filter was 273.8 NTU with average effluent turbidity of 9.08 NTU for sand and 6.62 NTU for Capped filter as shown in Figure 3.

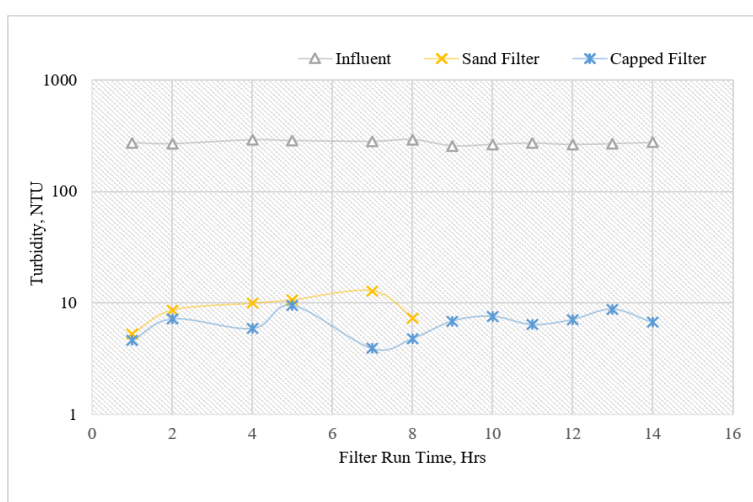

Figure 3: Effluent turbidity during seventh filter run

From first to third filter run, effluent turbidity produced by both sand and anthracite capped filter were below 5 NTU lower limit prescribed by NDWQS [5]. Anthracite capped filter has higher potential in turbidity removal for influent turbidity below 100 NTU. With further increase in influent turbidity from third to seventh filter run, the average effluent turbidity produces were above 5 NTU lower limit prescribed by NDWQS.

\subsection{Head Loss Development during Filter Run Time}

The allowable terminal head loss was $165.4 \mathrm{~cm}$ for both filter models. In first filter run, initial head loss for Sand filter was $15.1 \mathrm{~cm}$, whereas for Capped filter was 13.8 $\mathrm{cm}$. The Sand filter showed greater head loss throughout the run time with first exhaust at run time of 134 hours and Capped filter exhaust after 150 hours as shown in Figure 4.

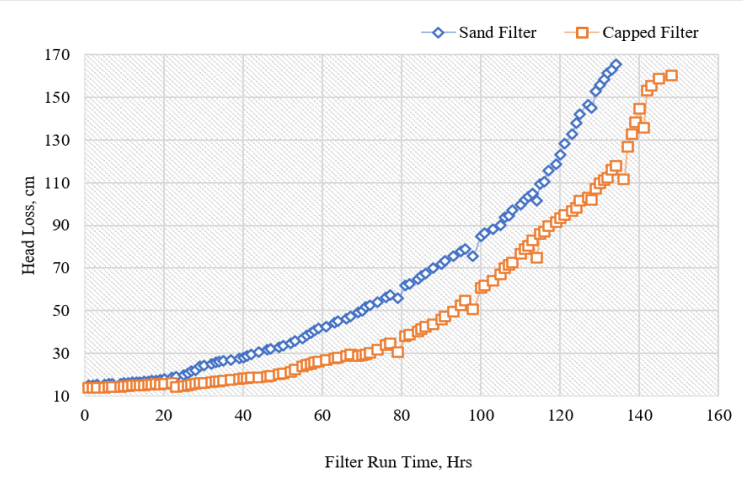

Figure 4: Head loss development during first filter run

In seventh filter run, initial head loss for sand filter and capped filter was $23.2 \mathrm{~cm}$ and $16.5 \mathrm{~cm}$ respectively. Sand filter exhausted at 8 hours whereas anthracite capped filter exhausted in 14 hours run time as shown in Figure 5. The development of head loss was rapid for both filter with increase in influent turbidity due to surface sealing or surfacing blinding of filter media. There was decrease in water head at the start of the filter run due to intermittent filter operation which is indicated by sudden drop in head loss value.

\subsection{Filter Run Time with Increase in Influent Turbidity}

Filter run length depends on the raw water characteristics. The filter run time for both filter models subjected to different influent turbidity value is shown in Figure 6. The maximum filter run time for sand filter was 134 hours and for anthracite capped filter was 150 hours for 


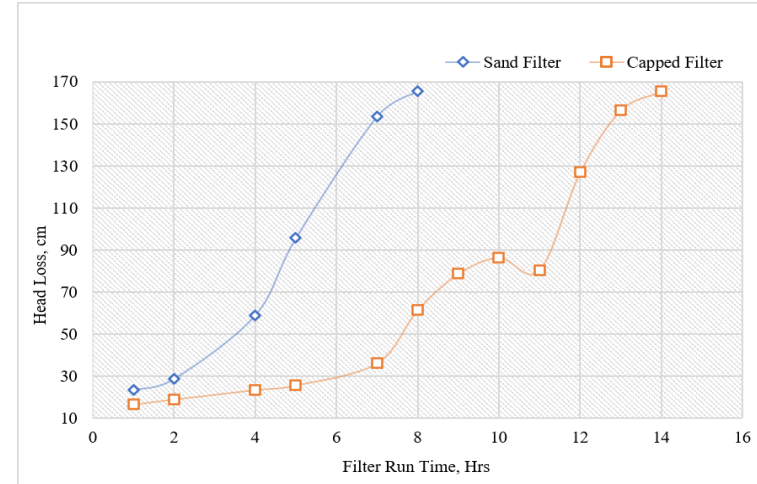

Figure 5: Head loss development during seventh filter run

average influent turbidity of 10.9 NTU during first filter run

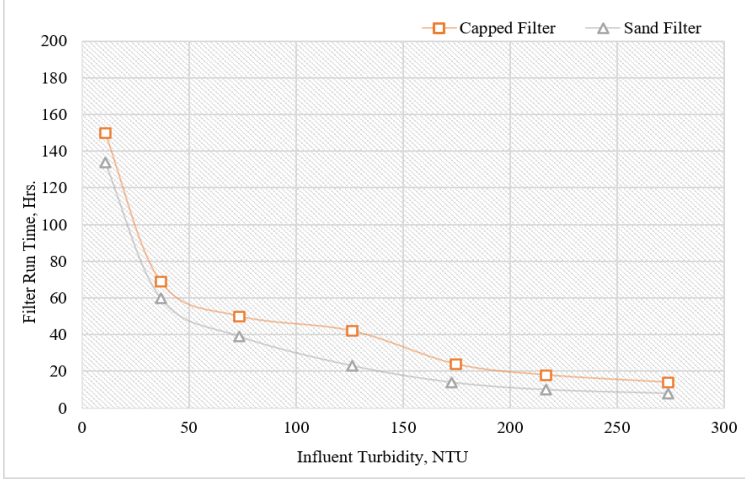

Figure 6: Filter run time with increase in influent turbidity

The Anthracite Capped Filter last longer than sand filter for average turbidity of 273.8 NTU with filter run time of 14 hours and 8 hours respectively in seventh filter run. The filter run time for capped filter was $11.9 \%$ (minimum) and $82.6 \%$ (maximum) more than that of sand filter in first and fourth filter run respectively. In average, the filter run time for anthracite capped filter was $52.03 \%$ more than that of sand filter.

\subsection{Head Loss Gained with Increase in Influent Turbidity}

The head loss gained in meter for different influent turbidity after producing filtrate of $100 \mathrm{~m}^{3} / \mathrm{m}^{2}$ area of filter is shown in Figure 7. The performance of the filter is indicated by the rate of head loss buildup during filter run. Sudden increase in head loss might be an indication of surface sealing of the filter media (lack of depth penetration).

In all filter runs, head loss gained for Sand filter was on

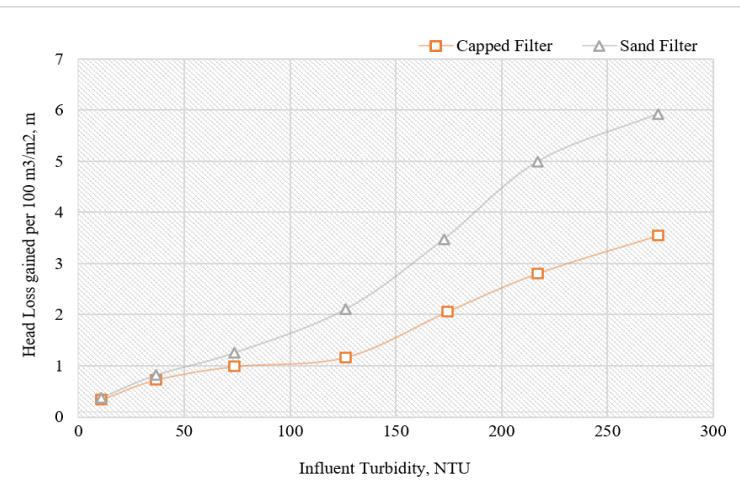

Figure 7: Head loss gained with increase in influent turbidity

the higher side, with maximum of $5.925 \mathrm{~m}$ for sand filter and $3.545 \mathrm{~m}$ for anthracite capped filter in seventh filter run and minimum of $0.374 \mathrm{~m}$ for sand filter and $0.337 \mathrm{~m}$ for anthracite capped filter in first filter run. Head loss gained for Sand filter was $11 \%$ (minimum) and $80.4 \%$ (maximum) more than that of capped filter in first filter run and fourth filter run respectively. In average, head loss gained for sand filter was $49.2 \%$ more than that of anthracite capped filter.

\subsection{Comparison of performance of conventional and capped rapid sand filter}

From the experimental study, it is observed that as filtration efficiency mainly depends on porosity of media used for filtration work. Anthracite coal has lesser specific gravity compared to sand and so larger particles remains on top after backwashing. It also provides larger depth for filtration and improves performance by removing larger suspended particles at initial stage. Maximum throughput volume can be achieved and also the run length is increased for anthracite capped filter in comparison to conventional sand filter due to porous nature.

\section{Conclusions}

The main aim of this research work was to find out the effectiveness of anthracite coal as capping media in rapid sand filter. Based on the study, some conclusions have been revealed:

i Capping proves an efficient technique for improving performance of rapid sand filters in terms of head loss development, filter run length and turbidity removal efficiency.

ii The produced effluent for influent turbidity below 100 NTU satisfied most stringent quality stan- 
dards. The influent turbidity therefore, above 100 NTU should be pretreated in order to meet required effluent turbidity standard.

iii Capped filter last longer than sand filter in all filter runs. The whole thickness of the media was utilized in the filtration process as opposed to the top layers of conventional rapid sand filters. In average, filter run length of anthracite capped filter increases by $52.03 \%$ than that of conventional rapid sand filter.

iv The head loss gained in meter after producing filtrate of $100 \mathrm{~m}^{3}$ per $\mathrm{m}^{2}$ area of filter for capped filter was on lower side showing its potential for high turbid water. In average, head loss gained for sand filter was $49.2 \%$ more than that of anthracite capped filter.

v The study highly stressed on necessity of this technique in the country water treatment plants for the various merits gained.

\section{Advantages}

i Higher service flows and longer filter runs than equivalent sand filters

ii Capping of conventional rapid sand filter can be very effective tool in case of overloaded conventional plants where higher rate of filtration can be possible without much modification.

iii The extra cost of importing anthracite coal could be substituted excessively by the wide ranges of merits of anthracite coal as filter media.

iv A great economic benefits could be achieved through operating at higher rates. Consequently more water was produced which avoids construction of new plants and/or reducing number of filter units by $50 \%$ in the plants and thus, reducing the plant cost.

\section{Future Scope}

Capping with anthracite coal shall proves very effective in improving performance of rapid sand filter in pilot scale. This material should be further studied and tested in full scale plant to access its suitability for mass scale filtration. Use of anthracite coal as capping media for longer period will give better performance analysis.

\section{Acknowledgement}

The authors are grateful to the M.Sc. in Sustainable Water Sanitation Health and Development, Norad's Pro- gramme for Master Studies (NOMA) program, Pulchowk Campus, Institute of Engineering, Tribhuwan University, Nepal for providing the part of the financial support necessary for this study.

\section{References}

[1] Sabale R, Mujawar S. Improved Rapid Sand Filter for Performance Enhancement[J/OL]. International Journal of Science and Research (IJSR), 2014, 3(10): 1031-1033. www.ijsr.net.

[2] Al-Rawi S M. Introducing sand filter capping for turbidity removal for potable water treatment plants of Mosul/Iraq[J]. International Journal of Water Resources and Environmental Engineering, 2009, 1(1): 011-019.

[3] Manoj M, Shashiraj C, Gopal B. Improvement of Performance of Rapid Sand Filter using Coconut Shell as Capping Media[J]. International Journal of Science and Research, 2014, 3(6): 22542257.

[4] Engelhardt T. Granular Media Filtration for Water Treatment Applications[R]. 2012: 1-61.

[5] Ministry of Physical Planning and Works. National Drinking Water Quality Standards[R]. Kathmandu, Nepal: Government of Nepal, 2005: 1. 